American Journal of Applied Sciences 6 (9): 1633-1636, 2009

ISSN 1546-9239

(C) 2009 Science Publications

\title{
Nucleotide Sequence of the Coat Protein Gene of the Malaysian Passiflora Virus and its 3' Non-Coding Region
}

\author{
${ }^{1}$ Norzihan Abdullah, ${ }^{2}$ Ismanizan Ismail, ${ }^{3}$ Vilasini Pillai, \\ ${ }^{4}$ Ruslan Abdullah and ${ }^{1}$ Shaiful Adzni Sharifudin \\ ${ }^{1}$ Biotechnology Center, Malaysian Agricultural and Research Development Institute, \\ G.P.O. Box 12301, Kuala Lumpur, Malaysia \\ ${ }^{2}$ School of Biosciences and Biotechnology, Faculty of Science and Technology, \\ University Kebangsaan Malaysia, 43600, Bangi, Malaysia \\ ${ }^{3}$ Ministry of Natural Resources and Environment, \\ Environmental Management Division, 62574, Putrajaya, Malaysia \\ ${ }^{4}$ Plantation Research, Sime Darby R and D Centre, 42960, Selangor, Malaysia
}

\begin{abstract}
Problem statement: In this study, we identified the full length Coat Protein $(\mathrm{CP})$ gene of the Malaysian Passiflora Virus (MPV) and its 3' non-coding region. The CP gene of the MPV contained 285 amino acid residues. Approach: Pairwise comparison of the MPV CP region with four other potyviruses, namely East Asian Passiflora Virus (EAPV), Passionfruit Woodiness Virus (PWV), Bean Common Mosaic Virus (BCMV) and Soyabean Mosaic Virus (SMV) revealed amino acid sequence similarities ranging from $72-95 \%$. Results: The 3' non-coding region of the MPV, which consists of 255 nucleotides, showed 69-95\% nucleotide sequence identity when compared with the four potyviruses. The highest (95\%) sequence similarities were detected with PWV and EAPV. An analysis of the deduced amino acid sequences revealed the presence of consensus motifs (DAG tripeptides) characteristic of potyviruses. DAG tripeptides had been reported to be essential for aphid transmission. Conclusion: From the amino acid sequence alignment and identity level observed among the four other potyviruses, we concluded that MPV is a member of the genus Potyvirus and was closely related to both PWV and EAPV.
\end{abstract}

Key words: Coat protein, passionfruit, plant virus, potyviruses

\section{INTRODUCTION}

Malaysian Passiflora Virus (MPV) is named after the virus that was isolated from the infected passionfruit plants grown in the Malaysian Agricultural Research and Development Institute (MARDI), Malaysia. MPV is a member of the potyvirus group which is known as the largest group of plant virus pathogens. It contains about 180 members and causes significant economic losses in agriculture ${ }^{[5]}$. The genome of potyviruses consists of a single stranded positive sense RNA nucleotide of about 10,000 bases which is encapsidated by about 20,000 copies of a single coat protein. The 5, end is covalently attached to a protein ( $\mathrm{VPg}$ ) with a molecular weight between 6,000-24,000 and the 3' end contains a polyadenylate region of varying length. The potyvirus genom expresses as a large polyprotein (ranging between 340 and $368 \mathrm{~K}$ depending on the potyvirus) and is subsequently cleaved into smaller polypeptides.

The pathogen derived resistance (via coat proteins or as recently proposed, RNA sequences) approach has been widely used in conferring virus resistance to plants ${ }^{[1,2]}$. Therefore, this identified MPV CP or RNA sequence could be used to genetically engineer virusresistant passionfruit plants.

\section{MATERIALS AND METHODS}

Total RNA was extracted from infected passionfruit leaves using the RNeasy ${ }^{\circledR}$ Plant Mini kit (Qiagen). cDNA was synthesized using the QIAGEN ${ }^{\circledR}$ OneStep RT-PCR kit and was subsequently cloned into the pGEM-T Easy plasmid. This recombinant plasmid is denoted as pNA. Later the cDNA from this clone was subcloned into pMR104a (and named pNAMR) and

Corresponding Author: Ismanizan Ismail, School of Biosciences and Biotechnology, Faculty of Science and Technology, University Kebangsaan Malaysia, 43600, Bangi, Malaysia Tel: +603-89215954 Fax: +603-89252698 
sent for sequencing. The nucleotide sequence of the subclone was sequenced by First BASE, Malaysia.

\section{RESULTS}

The 3'-terminal nucleotide sequence of Malaysian passiflora virus (1497 nucleotides) and its deduced amino acid sequence are shown in Fig. 1. Computer analysis of the nucleotide and deduced amino acid sequences revealed that MPV contains an open reading frame encoding the partial sequence of the MPV nib gene, a Coat Protein (CP) and a Non-Coding Region (NCR).

Passionfruit Woodiness Virus (PWV), East Asian Passiflora Virus (EAPV), Soyabean Mosaic Virus (SMV) and Bean Common Mosaic Virus (BCMV) (Fig. 2). The cleavage site for the coat protein gene of MPV was determined by aligning and comparing the MPV amino acid sequence with four other potyviruses namely The potyviral coat proteins are known to be released from longer precursors by proteolytic cleavage at a $\mathrm{Q} / \mathrm{G}, \mathrm{Q} / \mathrm{S}, \mathrm{Q} / \mathrm{A}$ or $\mathrm{Q} / \mathrm{T}$ dipeptide sequence ${ }^{[4,7]}$. From this comparison, it seemed that the MPV proteolytic processing site for the coat protein was at the $Q / S$ dipeptide. The MPV coat protein site begins at position 129 and ends at position 414. This region of approximately 285 amino acid residues constitutes the total coat protein size for the MPV. A conserved residue motif CSESVSLQ was observed near the CP cleavage site. This conserved motif (Fig. 2) differed by one peptide from other aligned potyviruses $(\text { CCESVSLQ })^{[3]}$. The deduced amino acid sequence of the MPV CP also consists of two conserved DAG triplets (Fig. 1, underlined), that may correlate with the high frequency of aphid transmissibility. The MPV open reading frame was terminated by a stop codon (Fig. 1, asterisks) followed by the 255 nucleotide NCR (excluding the poly-A tail). The NCR contained a consensus AG-GTGG-----CCACC sequence ${ }^{[6]}$ as shown in Fig. 1 (underlined).

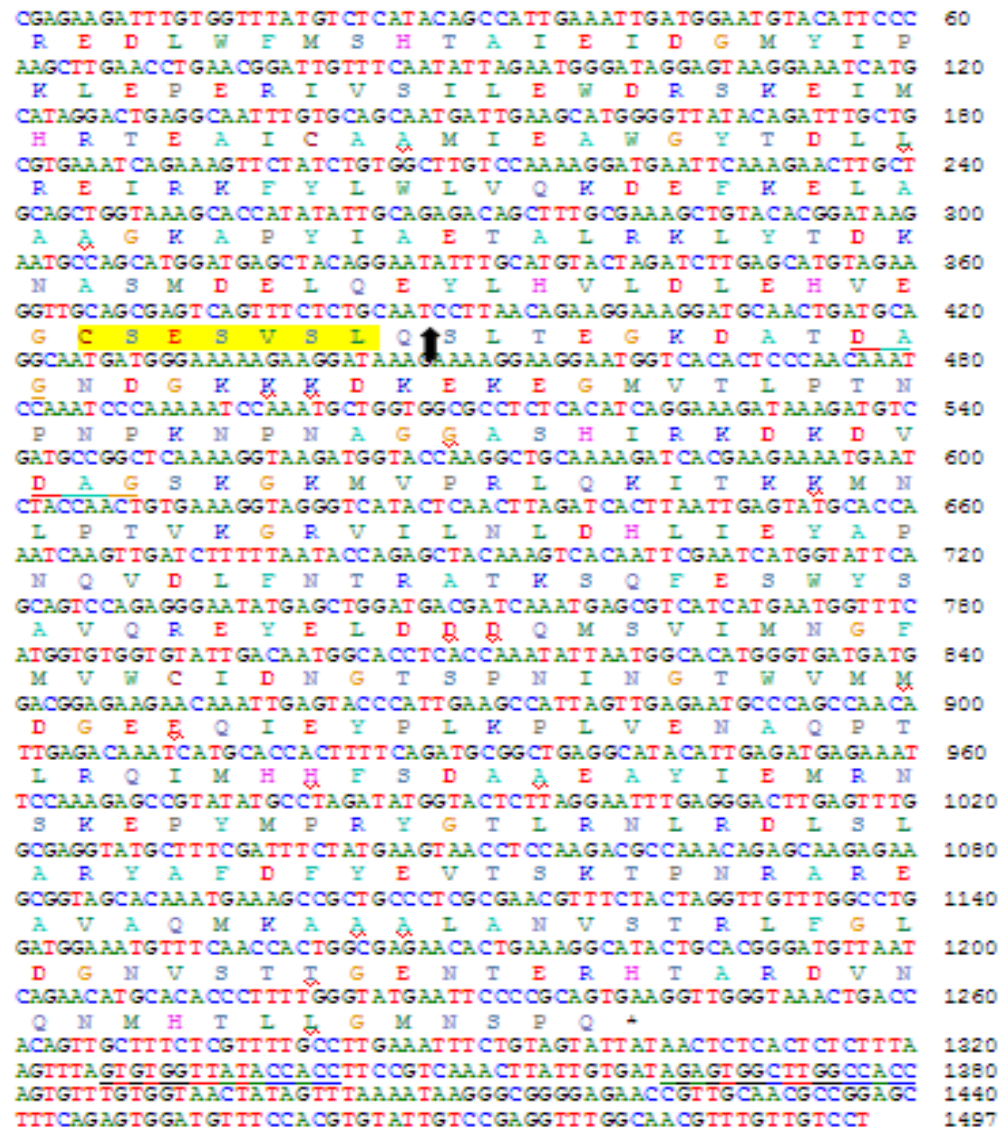

Fig. 1: Nucleotide sequence of the 3' terminal region of the MPV. The predicted amino acid sequences of the ORF is presented below the nucleotide sequence. The conserved motif (CSESVSL) within the ORF is highlighted in yellow. The putative cleavage site for the coat protein is indicated by, the stop codon is indicated by an asterisk and the consensus sequences in the NCR are underlined 


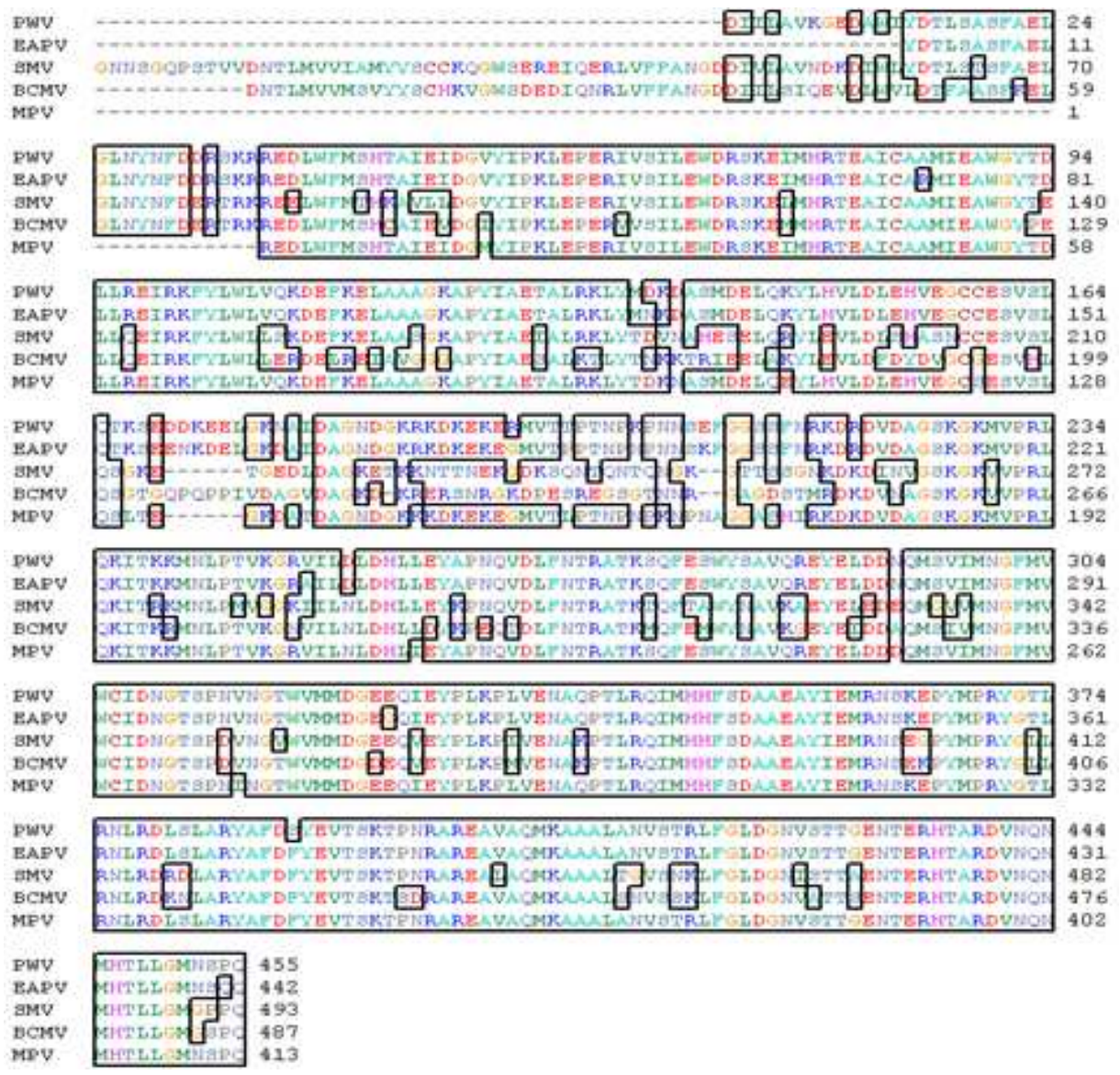

Fig. 2: Alignment of the amino acid sequences of five different potyviruses. The identical amino acids are boxed

\section{DISCUSSION}

Similarity studies were made between the sequence of MPV and those of other potyviruses in Genbank (http://blast.ncbi.nlm.nih.gov). Nucleotide and amino acid sequence comparisons were done using the BLASTN and BLASTX programs, respectively. About 74-91\% nucleotide sequence identity was observed when partial MPV nucleotide sequences were compared and about $72-84 \%$ similarity was observed in the BLASTX analysis (Table 1).

The nucleotide sequence of the 3' non-coding region (NCR) of the potyvirus RNA can also be used as basis for identifying and classifying potyviruses ${ }^{[3]}$. Distantly related potyviruses showed considerably different NCR lengths and displayed low sequence identity. In contrast, in related strains of the same virus, the size of the NCR is quite similar and shows high sequence similarity. From the pairwise NCR nucleotide analysis, it was observed that the MPV showed 69\% nucleotide sequence identity with SMV, $71 \%$ with BCMV and 95\% with both PWV and EAPV.
Table 1: Identity and similarity comparisons between MPV and four other potyviruses (PWV, EAPV, SMV and BCMV). BlastN and BlastX results were obtained by using BLAST programs from NCBI whereas pairwise percentage identities were carried out using the ClustalW program

\begin{tabular}{lllll}
\hline & & & $\begin{array}{l}\text { Pairwise percent } \\
\text { identity of CP } \\
\text { amino acids }\end{array}$ & $\begin{array}{l}\text { Pairwise percent } \\
\text { identity of the NCR } \\
\text { nucleotide sequence }\end{array}$ \\
Virus & BlastN $(\%)$ & BlastX $(\%)$ & 95 & 95 \\
PWV & 91 & 88 & 95 & 95 \\
EAPV & 91 & 87 & 73 & 69 \\
SMV & 74 & 75 & 72 & 71 \\
BCMV & 74 & 72 & & \\
\hline
\end{tabular}

From both $\mathrm{CP}$ amino acid and NCR nucleotide sequence analyses, a higher percentage of sequence identity was observed when MPV was compared with PWV and EAPV, but showed lower percentage when compared with SMV and BCMV (Table 1).

\section{CONCLUSION}

Based on these findings, we conclude that MPV is closely related to EAPV and PWV but distinct from BCMV and SMV. The 1497 nucleotide sequence data 
reported in this study has been deposited in GenBank under accession number EU035271.

\section{ACKNOWLEDGEMENT}

This research is funded by Malaysian Agriculture and research Development Institute (MARDI) and Ministry of Science, Technology and Innovation grant awarded to Ismanizan Ismail.

\section{REFERENCES}

1. Alfenas, P.F., A.S.K. Braz, L.B. Torres, E.N. Santana and A.V.S. Nascimento et al., 2005. Transgenic passionfruit expressing RNA derived from Cowpea aphid-borne mosaic virus is resistant to passionfruit woodiness disease. Fitopatologia Brasileira, 30: 1-12. DOI: 10.1590/S010041582005000100006

2. Dasgupta, I., V.G. Malathi and S.K. Mukherjee, 2003. Genetic engineering for virus resistance. Curr. Sci., 84: 341-354. http://www.ias.ac.in/currsci/feb102003/341.pdf

3. Frenkel, M.J., C.W. Ward and D. D. Shukla, 1989. The use of 3' Non-coding nucleotide sequences in the taxonomy of potyviruses: Application to watermelon mosaic virus 2 and Soyabean mosaic virus. N. J. Gen. Virol., 70: 2775-2783. http://vir.sgmjournals.org/cgi/reprint/70/10/2775
4. Iwai, H., J. Sakai and K. Hanada, 1997. Nucleotide sequence of the coat protein gene and 3' noncoding region of the passionfruit woodiness virus-Amami Ohshima isolate. Ann. Phytopathol. Soc. Jap., 63: 475-478.

http://rms1.agsearch.agropedia.affrc.go.jp/contents/ JASI/pdf/society/56-1981.pdf

5. Shukla, D.D., M.J. Frenkel and C.W. Ward, 1991. Structure and function of the potyvirus genome with special reference to the coat protein coding region. Can. J. Plant Path, 13: 178-191. http://www.cps-scp.ca/download/cjpparchive/Vol13/CJPP13(2)178-191(1991).pdf

6. Uyeda, I., 1992. Bean yellow mosaic virus subgroup; search for the group specific sequences in the 3' terminal region of the genome. Arch. Virol. Suppl., 5: 377-385. http://grande.nal.usda.gov/ibids/index.php?mode2= detail\&origin=ibids_references\&therow $=620701$

7. Vlugt, R.V., S. Allefs, P. De Haan and R. Goldbach, 1989. Nucleotide sequence of the 3' terminal region of potato virus Y RNA. J. Gen. Virol., 70: 229-233.

http://vir.sgmjournals.org/cgi/reprint/70/1/229 